NBER WORKING PAPER SERIES

\title{
THE PHILLIPS CURVE IS BACK? USING \\ PANEL DATA TO ANALYZE THE \\ RELATIONSHIP BETWEEN \\ UNEMPLOYMENT AND INFLATION \\ IN AN OPEN ECONOMY
}

\author{
John DiNardo \\ Mark P. Moore \\ Working Paper 7328 \\ http://www.nber.org/papers/w7328
}

NATIONAL BUREAU OF ECONOMIC RESEARCH

1050 Massachusetts Avenue

Cambridge, MA 02138

August 1999

We would like to thank Paul Beaudry, Thomas Buchmueller, Kaku Furuya, and Jack Johnston for useful discussions. We would also like to thank Richard Levich and Jaewoo Lee for providing forward exchange rate data. The views expressed herein are those of the authors and not necessarily those of the National Bureau of Economic Research.

(C) 1999 by John DiNardo and Mark P. Moore. All rights reserved. Short sections of text, not to exceed two 
paragraphs, may be quoted without explicit permission provided that full credit, including (C) notice, is given to the source.

The Phillips Curve is Back? Using Panel Data to Analyze the Relationship Between Unemployment

and Inflation in an Open Economy

John DiNardo and Mark P. Moore

NBER Working Paper No. 7328

August 1999

JEL No. E31, F41, J64

\section{ABSTRACT}

Expanding on an approach suggested by Ashenfelter (1984), we extend the Phillips curve to an open economy and exploit panel data to estimate the textbook "expectations augmented" Phillips curve with a market-based and observable measure of inflation expectations. We develop this measure using assumptions common in economic analysis of open economies. Using quarterly data from 9 OECD countries and the simplest econometric specification, we estimate the Phillips curve with the same functional form for the 1970s, 1980s, and 1990s. Our analysis suggests that although changing expectations played a role in creating the empirical failure of the Phillips Curve in the 1970s, supply shocks were at least as important.

John DiNardo

Department of Economics

University of California -- Irvine

Irvine, CA 92697-5100

and NBER

jdinardo@uci.edu
Mark P. Moore

Department of Economics

University of California -- Irvine

Irvine, CA 92697-5100

mpmoore@uci.edu 


\section{Introduction}

Although the Phillips curve is a staple of textbook macroeconomics (see, for example, the treatments in Blanchard (1997), Dornbusch, Fischer and Startz (1998) and Mankiw (1997)), it is difficult to state a consensus view about the relationship between unemployment and inflation. Ironically, there is general agreement on only one point - the empirical failure of the simple Phillips curve. Figure 1 displays the bivariate relationship between quarterly (annualized) inflation rates and (lagged) quarterly average unemployment rates for 9 OECD countries for the period 1970 to the end of 1982. Indeed, from these data it is hard to see any systematic relationship between unemployment and inflation, let alone the negative sloping line suggested by the textbook model of the Phillips curve.

The impression one receives from the pictures is confirmed by the slightly more formal analysis in Table 1, which presents Phillips curve estimates from the 9 OECD countries in our sample. Letting $j$ denote the country, and $t$ the quarter, our estimation equation is simply:

$$
\pi_{t}^{j}=a_{j}+\beta U_{t-1}^{j}
$$

where $\pi$ denotes inflation and $U$ the unemployment rate. We pool the data for our 9 OECD countries and include the country-specific intercepts $a^{j} .^{1}$

The estimates in column (2) correspond to the same sample period as Figure 1. The OLS point estimate of the coefficient on unemployment is -0.13 and not particularly well determined. As King and Watson (1994) have noted for the U.S., however, the period highlighted is exceptional if one

\footnotetext{
${ }^{1}$ In all fixed-effect regressions, we allow for a separate post 1991 intercept for Germany to account for unification.
} 
considers the relationship over the entire period since the 1960s. Figure 2 graphs the relationship between inflation and unemployment for the period 1983 to 1995 . While the fit is clearly imperfect, it is easier in these data to see the negative relationship predicted by the Phillips curve. Column (3) of Table 1 presents the OLS estimates of the simple Phillips curve for the more recent period. The point estimate of -0.42 for the unemployment coefficient is well within the range of more recent estimates (see the symposium in the Journal of Economic Perspectives (especially Gordon (1997) and Staiger, Stock and Watson (1997)). Over the entire sample period, the point estimate is -0.82 .

The intellectual history of the Phillips curve is familiar to most economists. In the wake of arguments by Friedman (1968) and Phelps (1968) in the late 1960s that the Phillips curve would not survive if policy makers tried to exploit it, and the "stagflation" of the 1970s, economists' views about the Phillips curve diverged sharply. No consensus seems to have emerged. Some economists "continu[e] to view the Phillips curve as essentially an intact structure" (Gordon 1997) and focus on more sophisticated time-series analysis and different functional forms for the relationship, while others dismiss the Phillips curve relationship as an "econometric failure on a grand scale" (Lucas and Sargent 1978). Those in the former group cite supply shocks (specifically unexpected increases in the price of oil) as one cause of the empirical failure of the Phillips Curve in the 1970s. However, in common with those who dismiss the Phillips curve as (at best) a statistical epiphenomenon, many in this group suggest that "the main reason was [that] firms and workers changed the way they formed expectations" (Blanchard 1997). 
This consensus about the primary role of expectations for the failure of the Phillips curve has a serious limitation: expectations are difficult to subject to empirical examination. We address this problem by developing a simple and natural extension of the textbook Phillips curve for an open economy, and applying standard reasoning from international economics to develop a measure of inflation expectations. In so doing, we also confront the issues of the appropriate price index to use in computing inflation and the dependence of the consumer price index on international prices, and extend the concept of a natural rate of unemployment to an open economy.

Our primary motivation is empirical. With our open economy extension, and from an identification strategy based on exploiting the power of panel data, we can estimate a simple Phillips curve with supply shocks and inflation expectations. Moreover, we can use the same functional Phillips relation to explain the 1970's, the 1980s, and the 1990s. The open-economy, panel data approach also allows us to investigate the relative importance of the two mechanisms - supply shocks and changing inflation expectations - alleged to have been responsible for the failure of the Phillips curve in the 1970s.

Our panel data strategy was first suggested by Ashenfelter (1984), who observed that when countries had similarly-sloped Phillips curves, supply shocks were common across countries, and differences in inflation expectations across countries could be ignored, transforming data by "countrydifferencing" could produce consistent estimates of the simple Phillips curve relation when the standard (untransformed) data would not. Using data for the U.S., U.K. and Canada (three countries for which it might be reasonable to assume similar inflation expectations), Ashenfelter found that, rather 
then falling apart in the 1970's, the estimated Phillips curve relations were remarkably robust.

Building on Ashenfelter (1984) and developing a natural open-economy extension of the textbook "expectations-augmented" Phillips curve model we can avoid relying on difficult-to-test assumptions about expectation formation. Our extension also provides a theoretically sound, market-based, and observable measure of relative inflation expectations with which we are able to estimate directly the textbook model. Using data from 9 OECD countries, and the simplest possible econometric specification, we find that our estimates of the Phillips curve are remarkably robust. Our results are consistent with an important role for expectations, but they also suggest that supply shocks had much to do with the poor performance of the Phillips curve in the 1970s.

The rest of the paper is organized as follows. First we provide a brief sketch of the textbook Phillips curve model and show how standard assumptions in open economy macroeconomics can be used to generate an observable measure of relative inflation expectations. Next we take this framework to the data and show that it provides remarkably robust estimates of the Phillips curve. Our final section discusses the implications of our results.

\section{Empirical Framework}

For any country $i$, the standard expectations-augmented Phillips relation is given by:

$$
\pi_{t, g d p}^{j}=\alpha E\left[\pi_{t, c p i}^{j}\right]+\beta\left(U_{t-1}^{j}\right)+a^{j}+z_{t}
$$


where $\pi_{g d p}$ denotes inflation in domestically produced goods (the percentage change in the GDP deflator), $\pi_{c p i}$ consumer price inflation, $U$ the unemployment rate, $a$ a country-specific constant term, and $z_{t}$ a common supply shock. Following standard treatments, we interpret this equation as an aggregate supply curve possibly subject to a set of common shocks $z_{t}$ and therefore expect $\beta<0$. Expected inflation affects wage-setting because workers care about their real consumption wage. Therefore, consumer price inflation is appropriate on the right hand side of equation (2). Domestic price setting depends on domestic nominal wages. Therefore, inflation in domestically produced goods is appropriate on the left hand side.

In a closed economy (where GDP inflation equals CPI inflation), the natural rate hypothesis boils down to $\alpha=1-i . e$, in the absence of supply shocks, the unemployment rate equals a constant (the natural rate) when expected inflation equals actual inflation. This condition will turn out to be the same for an open economy. However, we will not impose it at the outset, but rather estimate $\alpha$.

Closed economy variants of the Phillips relation arise from substituting different values for expected inflation and (often) imposing $\alpha=1$. For example, in a closed economy, the non-accelerating rate of inflation (NAIRU) characterization of the natural rate of unemployment arises from substituting lagged inflation for expected inflation, imposing $\alpha=1$, and generating a relation between the difference in inflation and the unemployment rate.

To exploit variation in panel data, we will assume that each country faces the same Phillips curve apart from a (possibly) different natural rate. We further assume that labor is not mobile between countries. Given the 
empirical work that follows it will be helpful to think of the U.S. as the reference country. Denote the U.S. as country $\star$ and observe that

$$
\begin{aligned}
\pi_{t, g d p}^{j}-\pi_{t, g d p}^{\star} & =\alpha E_{t-1}\left[\pi_{t, c p i}^{j}\right]+\beta U_{t-1}^{j}+a^{j}-\alpha E_{t-1}\left[\pi_{t, c p i}^{\star}\right]-\beta U_{t-1}^{\star}-a^{\star} \\
& =\alpha\left(E_{t-1}\left[\pi_{t, c p i}^{j}\right]-E_{t-1}\left[\pi_{t, c p i}^{\star}\right]\right)+\beta\left(U_{t-1}^{j}-U_{t-1}^{\star}\right)+a^{j}-a^{\star}
\end{aligned}
$$

This expression, which removes the common supply shock $z_{t}$ by differencing, is essentially the one derived by Ashenfelter (1984), except that we take explicit note of the different price indices on the left- and right-hand side of the equation. We depart from Ashenfelter by deriving an expression for the expected inflation differential between country $j$ and the U.S.

We begin by summarizing relative aggregate demand as a function of the real interest rate differential:

$$
g_{t-1}^{j}=r_{t-1}^{j}-r_{t-1}^{\star}=i_{t-1}^{j}-E_{t-1}\left[\pi_{t, c p i}^{j}\right]-i_{t-1}^{\star}+E_{t-1}\left[\pi_{t, c p i}^{\star}\right]
$$

The term $g^{j}$ includes relative policy shocks and is clearly correlated with the difference in unemployment rates (implied by differences in aggregate demand) between country $j$ and the U.S.

Now let $i$ stand for the nominal interest rate and $f d$ for the percentage forward discount on the currency of country $j$ relative to the U.S. dollar. Substitute covered interest parity

$$
i_{t-1}^{j}-i_{t-1}^{\star}=f d_{t-1}^{j}
$$


into equation (3) to obtain

$$
E_{t-1}\left[\pi_{t, c p i}^{j}-\pi_{t, c p i}^{\star}\right]=f d_{t-1}^{j}-g_{t-1}^{j}
$$

Substituting the latter equation into the U.S.--differenced Phillips curve gives:

$$
\pi_{t, g d p}^{j}-\pi_{t, g d p}^{\star}=\alpha f d_{t-1}^{j}-\alpha g_{t-1}^{j}+\beta\left(U_{t-1}^{j}-U_{t-1}^{\star}\right)+a^{j}-a^{\star}
$$

Given equation (6) one might be tempted to regress country-differenced GDP inflation on the forward discount and the lagged country-differenced unemployment rate. The difficulty with this approach, however, is the familiar problem of omitted variable bias: the omitted variable $g_{t-1}$ - last period's demand shock - is correlated with the lagged unemployment rate.

Recognizing this limitation, we proceed in three steps. First, we use equation (3) and uncovered interest parity to derive an expression for the percentage change in the real exchange rate. Next, we derive an expression for the difference between relative CPI inflation and relative GDP inflation. These two steps allow us to take the final step of rewriting equation (6) in a form suitable for estimation by recasting it as relationship between CPI inflation, the forward discount, and the difference in unemployment rates between country $j$ and the U.S.

First, recall the uncovered interest parity condition (UIP):

$$
i_{t-1}^{j}=i_{t-1}^{\star}+E_{t-1}\left[\partial \log e_{t}^{j}\right]+R P^{j}
$$

where $e^{j}$ is the nominal exchange rate in units of the currency of country $j$ 
per U.S. dollar and $R P^{j}$ is the risk premium on country $j$ 's assets relative to U.S. assets. We assume that the risk premium is constant. Substitute UIP into equation (3) to obtain

$$
E_{t-1}\left[\pi_{t, c p i}^{j}-\pi_{t, c p i}^{\star}-\partial \log e_{t}^{j}\right]=\pi_{t, c p i}^{j}-\pi_{t, c p i}^{\star}-\partial \log e_{t}^{j}-\epsilon_{t}^{j}=R P^{j}-g_{t-1}^{j}
$$

where $\epsilon_{t}^{j}$ is an error term that is orthogonal to the information set at time $t-1$.

Now assume that inflation in nontradables is equal to GDP inflation, and let $\pi_{t}^{w}$ denote world inflation in dollars of the tradable goods component of consumption. With the additional assumption that countries share a common consumption basket, and letting $\rho$ denote the share of consumption devoted to nontradables equation (8) implies: ${ }^{2}$

$$
\rho \pi_{t, g d p}^{j}+(1-\rho)\left[\partial \log e_{t}^{j}+\pi_{t}^{w}\right]-\rho \pi_{t, g d p}^{\star}-(1-\rho) \pi_{t}^{w}-\partial \log e_{t}^{j}=R P^{j}-g_{t-1}^{j}+\epsilon_{t}^{j}
$$

or

$$
\pi_{t, g d p}^{j}-\pi_{t, g d p}^{\star}-\partial \log e_{t}^{j}=\frac{R P^{j}-g_{t-1}^{j}+\epsilon_{t}^{j}}{\rho}
$$

Second, use equations (8) and (10) to express relative CPI inflation in terms of relative GDP inflation:

$$
\pi_{t, c p i}^{j}-\pi_{t, c p i}^{\star}=\pi_{t, g d p}^{j}-\pi_{t, g d p}^{\star}+\frac{1-\rho}{\rho}\left(g_{t-1}^{j}-R P^{j}-\epsilon_{t-1}^{j}\right)
$$

\footnotetext{
${ }^{2}$ The left hand side of equation (9) is the difference in CPI inflation between country $j$ and the U.S. minus depreciation of country $j$ 's currency relative to the dollar. Note that the tradable component of U.S. CPI inflation does not include an exchange-rate term, since we denominate inflation in tradables in dollars.
} 
Our third and final step is to rewrite this expression in a form suitable for estimation. Use equation (5) to solve for $g$

$$
g_{t-1}^{j}=f d_{t-1}^{j}-\left(\pi_{t, c p i}^{j}-\pi_{t, c p i}^{\star}\right)+\nu_{t}^{j}
$$

(where $\nu^{j}$ is the expectational error in relative CPI inflation for country $j$ ), substitute this solution and the U.S.-differenced Phillips curve into equation (11), and rearrange to obtain

$$
\begin{array}{r}
\pi_{t, c p i}^{j}-\pi_{t, c p i}^{\star}=\frac{1-\rho}{1-\rho \alpha} f d_{t-1}^{j}+\frac{\beta \rho}{1-\rho \alpha}\left(U_{t-1}^{j}-U_{t-1}^{\star}\right) \\
-\left[\frac{\rho}{1-\rho \alpha}\left(a^{j}-a^{\star}\right)-\frac{1-\rho}{1-\rho \alpha} R P^{j}\right]-\frac{1-\rho}{1-\rho \alpha} \epsilon_{t}^{j}+\frac{1-\rho-\rho \alpha}{1-\rho \alpha} \nu_{t}^{j}
\end{array}
$$

or, with suitable definitions,

$$
\pi_{t, c p i}^{j}-\pi_{t, c p i}^{\star}=\widetilde{\alpha} f d_{t-1}^{j}+\widetilde{\beta}\left(U_{t-1}^{j}-U_{t-1}^{\star}\right)+\gamma^{j}+\mu_{t}^{j}
$$

Equation (13), which we call the open economy Phillips curve, is the basis for the empirical work that follows in the remainder of the paper. We note two points.

First, in an open economy, unemployment should be at its natural rate when the real exchange rate is on its trend growth path-i.e., when $g$ is a constant-or equivalently, when the real interest rate differential is constant. By equation (11), this implies that CPI inflation equals GDP inflation, up to a constant. Thus, if $\alpha=1$, the relative unemployment rate will be a constant when expected inflation equals actual inflation. This constant unemployment rate-the open economy natural rate-will be a function of the trend rate of 
real depreciation, among other things.

Second, observe that $\widetilde{\alpha}$ and $\widetilde{\beta}$, the coefficients on the forward discount and the difference in unemployment rates, are not the coefficients that describe the aggregate supply curve. As our concerns are primarily empirical - we are interested in the relationship between inflation, unemployment, and inflation expectations - this is not a problem. It is interesting to note, however, that to the extent that traditional estimates of the Phillips curve use incorrect price indices or imprecise measures of inflation expectations (e.g., lagged inflation), this analysis suggests that such estimates do not capture the true aggregate supply relation. It is true, however, that the coefficients are informative about the aggregate supply curve: $\widetilde{\alpha}>1$ implies $\alpha>1$ and (as long as $\rho \alpha<1) \widetilde{\beta} \lesseqgtr 0$ implies $\beta \lesseqgtr 0 .^{3}$

Finally, we observe that the derivation of equation (13) requires three assumptions:

1. the consumption share of nontradables is the same across countries;

2. $\beta$, the coefficient on unemployment, is the same across countries; and

3. the risk premium in UIP is constant over time.

The first two assumptions exploit the power of the panel. We explore the implications of partially relaxing the second assumption in our discussion of the empirical results. The third assumption is arguably a tolerable approximation for the countries in our sample. This assumption concerns the use of

\footnotetext{
${ }^{3}$ The above derivation also implies that we can recover $\alpha$ and $\beta$ from $\widetilde{\alpha}$ and $\widetilde{\beta}$ if we know $\rho$. Although our focus will be on the estimates of $\widetilde{\alpha}$ and $\widetilde{\beta}$, we will discuss a technique for estimating $\rho$, implement it, and recover $\alpha$ and $\beta$ below.
} 
the forward discount as a measure of inflation expectations. We discuss this issue in the final section of the paper.

\section{Data}

To estimate (13), we need data on inflation, unemployment, and the forward discount for a cross section of countries. We use average quarterly CPIs and nonstandardized average quarterly unemployment rates from the OECD, Main Economic Indicators. The unemployment data were assembled by Bianchi and Zoega (1998). ${ }^{4}$ Inflation is defined as the log difference in the CPI. We obtain three-month forward discounts and spot exchange rates from a widely-used data set assembled by Richard Levich from a continuous publication of Harris Bank. Throughout, we use the forward discount at the end of the preceding period as the measure of inflation expectations. Thus, to estimate (13), an observation for country $i$ for 1980:1 would include the 1980:1 inflation rate and the 1979:4 unemployment rate, both differenced with respect to the U.S. values, and the three-month forward discount as of the end of December, 1979. Note that for ease of interpretation we annualize the quarterly inflation rates and forward discounts.

We end up with a sample of 9 OECD countries (including the U.S. as the base country), with varying sample lengths, which are presented below. ${ }^{5}$

\footnotetext{
${ }^{4}$ The use of the standardized OECD unemployment rates makes no difference to the empirical results. The non-standardized rates, however, are available for a longer time period.

${ }^{5}$ The sample for Japan begins in 1972:4 when we use the forward discount. We use this sample for all country-differenced regressions, i.e., Tables 2-4.
} 


\begin{tabular}{lc} 
Country & Sample Period \\
\hline Belgium & $1970: 2-1996: 1$ \\
Canada & $1970: 2-1996: 1$ \\
France & $1970: 2-1996: 1$ \\
Germany & $1970: 2-1995: 4$ \\
Italy & $1970: 2-1995: 3$ \\
Japan & $1970: 2-1995: 4$ \\
Netherlands & $1970: 2-1995: 4$ \\
United Kingdom & $1970: 2-1995: 2$ \\
United States & $1970: 2-1996: 1$
\end{tabular}

\section{Empirical Results}

Table 2 presents the results of the estimation. The first half of the table (columns (1) - (6)) report the results from using the specification suggested by Ashenfelter (1984) with all the countries in the sample. The point estimates and standard errors are generally robust to choice of technique, but for completeness, we present results using OLS and generalized least squares allowing for heteroskedasticity and country-specific AR(1) errors. We estimate the results for the entire sample period, the period before 1983 - the period when the Phillips curve "failed", and the period after 1982. We choose the end of 1982 as the dividing line because it represents the end of the Volcker monetary experiment and because it divides our sample neatly in half. The specification in the first six columns of Table 2 is strictly appropriate only if the difference in inflation expectations between countries is constant or more generally orthogonal to the country differences in unemployment rates. ${ }^{6}$ We

\footnotetext{
${ }^{6}$ Note that this specification, which does not include the forward discount, would also be appropriate in a closed economy (since $\rho=1$ ), and, in this case, the estimated coefficient
} 
find that the estimates are remarkably robust. Far from falling apart in the 1970s, the estimates are consistent with a somewhat more negatively sloped Phillips curve. The simple $R^{2} \mathrm{~s}$ in the first three columns range from 0.34 to 0.41 .

Columns (7) - (12) show the estimates derived from our open economy Phillips curve and include the forward discount. The slope of the Phillips curve becomes somewhat less steep - the point estimates range from -0.47 to -0.79 depending on the choice of estimation technique or time period and are fairly well-determined. The point estimate on the forward discount is 0.38 in the whole sample using OLS and 0.31 when we use GLS instead. With the exception of the OLS estimate using only the post-1982 sample (a period when presumably changes in inflation expectations have been less important), the estimates on the forward discount coefficient are different from zero at conventional levels of significance.

The inclusion of the inflation expectations measure generally makes a relatively small difference in the estimated coefficient on relative unemployment (compare columns 7-12 with columns 1-6 in Table 2). This suggests that common supply shocks rather than changing inflation expectations are the primary reason for the failure of the Phillips Curve in the 1970s. Of course, country differencing may also remove common changes in inflation expectations across countries, so we cannot completely disentangle the effects. We also note that we can generally reject the hypothesis that the coefficient on differences in inflation expectations is equal to 1 - strictly interpreted this is

on the country-differenced unemployment rates would be the $\beta$ from the aggregate supply curve if $\alpha=0$, i.e., if expectations were irrelevant for inflation. See the derivation of equation (13). 
a rejection of the natural rate hypothesis. We return to this point below.

Without abandoning our panel data approach, but at the cost of estimating many additional parameters, we take a step in relaxing our assumption that the coefficients are the same for all pairs of countries. Table 3 presents country-by-country estimates of our open-economy Phillips curve. These estimates use the Prais-Winsten technique to account for serial correlation in the error terms. Not surprisingly, our estimates are less precise, but they provide support for our panel data strategy as the OLS estimates are very similar across countries. The estimated coefficients on relative unemployment all negative for all countries and for all but three of these countries (Belgium, Germany, and Japan) the estimates are different from zero at conventional levels of significance. Apart from the U.K. (with an estimated coefficient of -0.85) and Japan (with an estimated coefficient of -.12) the remaining coefficients range from -.33 to -.59 - compare this to our the GLS panel estimate of -0.47 .

Likewise, the point estimates on the forward discount coefficient are strikingly similar across the sample countries. All but three (Canada, Germany, and the Netherlands) are different from zero at conventional levels. The coefficient for the UK is largest (0.47) and the smallest is for the Netherlands (0.14). The remaining coefficients range from 0.22 to 0.41 - this can be compared to our pooled GLS estimate of 0.31. As we discuss below, it is interesting to observe that all the estimates are significantly less than one in the context of our model, we can reject the natural rate hypothesis. 


\section{Discussion}

If one accepts the stability of the open economy Phillips curve, it is natural to ask what guidance it provides policymakers. Apart from the Lucas critique, there are two obvious limitations. First, the country-differencing approach removes common supply shocks and produces a relationship between relative inflation and relative unemployment. The actual inflation rate in a given country would depend on supply shocks. Second, expectations do matter in our estimated Phillips curves. To the extent that changes in policy affect expectations about inflation, they will also affect inflation.

On the latter point, our finding that the estimated coefficient on expected inflation is less than one seems to call into question the typical natural rate hypothesis, in which the natural rate is defined as that unemployment rate which occurs when expected inflation equals actual inflation. According to our estimates, in order for the unemployment rate to be constant, expected inflation would have to exceed actual inflation.

Recall from section III that the point estimates in the table are not identical to the parameters of the aggregate supply relation, except in the case where the inflation moves one-for-one with inflation and the share of nontradables in consumption is zero. Even when inflation moves one-for-one the estimated coefficients conflate two different "structural" parameters - the slopes of the aggregate supply relation and $\rho$ - the share of consumption in non-tradable goods.

As we also noted, the theoretical model developed above, however, does provide a rather simple method to recover the aggregate supply relation. Equations (11) and (12) imply that the coefficient on the (country-differenced) 
GDP inflation in a regression of relative CPI inflation on relative GDP inflation and the forward discount (and a set of country fixed effects) provides a simple estimate of $\rho .^{7}$ Intuitively, if all consumption is domestic consumption - the economy is closed - the two measures are identical up to a constant and random error and the coefficient on relative GDP inflation will be one.

When we perform this exercise, we get an estimate of $\rho=.90 .^{8}$ Our motivation for $\rho$ was the share of nontradables in consumption. In fact, it should be interpreted a bit more broadly, as the percentage of CPI inflation attributable to domestic wage inflation. Thus, $\rho$ would incorporate the nontradable share of consumption and the retail component of tradable consumption. The latter component is cited as a reason for the divergence of traded goods prices across the world.

Given our estimate of $\rho$ and our estimates of $\widetilde{\alpha}$ and $\widetilde{\beta}$, we can "back out" the underlying estimates of the aggregate supply relation. To give some sense for what this implies consider the following estimates (using our GLS results for the full sample in Table 2) for the aggregate supply curve ${ }^{9}$ :

\footnotetext{
${ }^{7}$ Our approach also implies the need for instrumental variable estimation. Our estimating equation (implied by the definitions of the price indices and uncovered interest parity) is

$$
\pi_{t, c p i}^{j}-\pi_{t, c p i}^{\star}=\rho\left(\pi_{t, g d p}^{j}-\pi_{t, g d p}^{\star}\right)+(1-\rho) f d_{t-1}^{j}+\widetilde{\gamma}^{j}+\mu_{t}^{j}
$$

where $\mu$ is an (expectational) error uncorrelated with the information set at time $t-1$. Since $\mu_{t}$ is correlated with the difference in GDP inflation at time $t$, we instrument GDP inflation with its lag.

${ }^{8}$ To carry out this exercise, we obtain GDP deflators from the OECD Main Economic Indicators, and define GDP inflation as the log difference in the GDP deflator. The OECD sample for GDP inflation excludes Belgium, and begins in 1977:2 for the Netherlands, and 1992:1 for Germany. We replace the OECD series for Germany with an IMF series, which spans our original sample period. Our estimate of $\rho$ - the coefficient on (instrumented) relative GDP inflation - is .90 (.094) and our estimate of $(1-\rho)$ - the coefficient of the forward discount - is .13 (.047). We cannot reject the hypothesis that the sum of these coefficients is one.

${ }^{9}$ The numbers in parentheses are the appropriate interquartile ratio from a parametric
} 


$$
\pi_{t, g d p}^{j}-\pi_{t, g d p}^{\star}=\begin{array}{ccccc}
.78 & f d_{t-1}^{j} & - & .139 & \left(U_{t-1}^{j}-U_{t-1}^{\star}\right) \\
(.053) & & & (.038)
\end{array}
$$

Although we do not wish to stress this aspect of the findings, we note that given our estimate for $\rho$, the relationship between relative CPI inflation and expected relative CPI inflation (the open economy Phillips curve) is weaker than the relationship between GDP inflation and expected CPI inflation (the domestic aggregate supply relation), although in both cases we can reject the hypothesis that the coefficient on expected inflation is one. On the other hand, the sensitivity of relative CPI inflation to the country-differenced unemployment rate is stronger than the sensitivity of relative GDP inflation to the country-differenced unemployment rate.

Another issue which we wish to address is whether our measure of inflation expectations may be plagued by the same problems that bedevil empirical work on the foreign exchange market. In particular, the forward discount bias finding in the international finance literature seems to imply that uncovered interest parity, equation (7), does not hold. ${ }^{10}$ On this point, we make three observations.

First, our result is not an anomaly of our data set. Indeed, we have practically the entire flexible rate period in our sample. For our data set, the "Fama regression" of actual depreciation against the forward discount and a set of country fixed effects yields a coefficient (statistically insignificant from zero) of -0.07 . Standard theory predicts a coefficient of one. The results $\overline{\text { bootstrap using } \alpha=0.31(0.035), \beta}=-0.47$ (0.061) with 10,000 replications, assuming a fixed value for $\rho=0.91$.

${ }^{10}$ See Lewis (1995). 
are similar (the coefficient falls to -0.14 , but remains insignificant) when we include unemployment differentials in the regression. So we have not solved the forward discount bias puzzle. Despite this, the forward discount still seems to predict inflation.

Second, we note that the coefficient on relative unemployment does not change much when we use relative lagged inflation as the measure of inflation expectations. Table 4 presents these results using relative lagged inflation. We also try using both the forward discount and relative lagged inflation. Again, the estimated coefficients on relative unemployment are similar to our baseline estimate (compare columns 7-12 in Tables 2 and 3). The inclusion of lagged inflation also has only a small effect on the coefficient on the forward discount, even though the estimated coefficients on lagged inflation are significantly different from zero. We note that we can easily reject that the coefficients on the forward discount and relative lagged inflation sum to one. We believe that the forward discount is a better measure of expected relative inflation because it is a forward-looking and market-based measure, with some tie to theory. Nevertheless, it is comforting that the coefficient on relative unemployment is robust to the measure of inflation expectations.

Third, a common strategy for estimating a modern Phillips curve is to choose lagged inflation as the measure of inflation expectations and impose a coefficient of one. The difference in inflation is then regressed against unemployment. This gives rise to the NAIRU characterization of the natural rate. We experiment with this technique by subtracting the forward discount from relative inflation, and regressing the result against relative unemploy- 
ment and fixed effects. ${ }^{11}$ Using OLS, we obtain an estimated coefficient on relative unemployment of -0.33 , with a standard error of 0.059 . The GLS estimate is -0.34 , with a standard error of 0.081 . These estimates compare to our estimates of -0.48 (OLS) and -0.47 (GLS) when the coefficient on the forward discount is unrestricted.

In sum, we believe that our results show a remarkably robust relationship between relative inflation and relative unemployment. Our results also suggest that country-differencing may be a useful empirical strategy in research on open economies.

\footnotetext{
${ }^{11}$ Note from the derivation of equation (13) that the restriction $\alpha=1$ implies that the coefficient on the forward discount is one.
} 


\section{References}

Ashenfelter, Orley, "Macroeconomic and Microeconomic Analyses of Labor Supply," Carnegie-Rochester Conference Series on Public Policy, Autumn 1984, 21, 117-155.

Bianchi, M. and G. Zoega, "Unemployment Persistence: Does the Size of the Shock Matter?," Journal of Applied Econometrics, May-June 1998, 13 (3), 283-304.

Blanchard, Olivier, Macroeconomics, 1st ed., Upper Saddle River, N.J.: Prentice Hall, 1997.

Dornbusch, Rudiger, Stanley Fischer, and Richard Startz, Macroeconomics, 7th ed., Boston: McGraw-Hill/Irwin, 1998.

Friedman, Milton, "The Role of Monetary Policy," American Economic Review, 1968, 58 (1), 1-17.

Gordon, Robert J., "The Time-Varying NAIRU and Its Implications for Economic Policy," Journal of Economic Perspectives, Winter 1997, 11 (1), 11-32.

King, Robert G. and Mark W. Watson, "The Post-War U.S. Phillips Curve: A Revisionist Econometric History," Carnegie-Rochester Conference Series on Public Policy, 1994, 41, 157-219.

Lewis, Karen K., "Puzzles in International Financial Markets," in Gene M. Grossman and Kenneth Rogoff, eds., Handbook of International Economics, Vol. 3, Amsterdam: Elsevier, 1995, chapter 3, pp. 1913-1971.

Lucas, Robert E. Jr. and Thomas Sargent, "After Keynesian Econometrics," in "After the Phillips Curve: Persistence of High Inflation and High Unemployment" number 19. In 'Conference Series.', Boston: Federal Reserve Bank of Boston, 1978, pp. 49-72.

Mankiw, N. Gregory, Macroeconomics, 3rd ed., New York: Worth Publishers, 1997.

Phelps, Edmund, "Money-Wage Dynamics and Labor-Market Equilibrium," Journal of Political Economy, August 1968, pp. 678-711. 
Staiger, Douglas, James Stock, and Mark W. Watson, "The NAIRU, Unemployment and Monetary Policy," Journal of Economic Perspectives, Winter 1997, 11 (1), 33-49. 
Source: CPIs and Non-Standardized Unemployment Rates, OECD
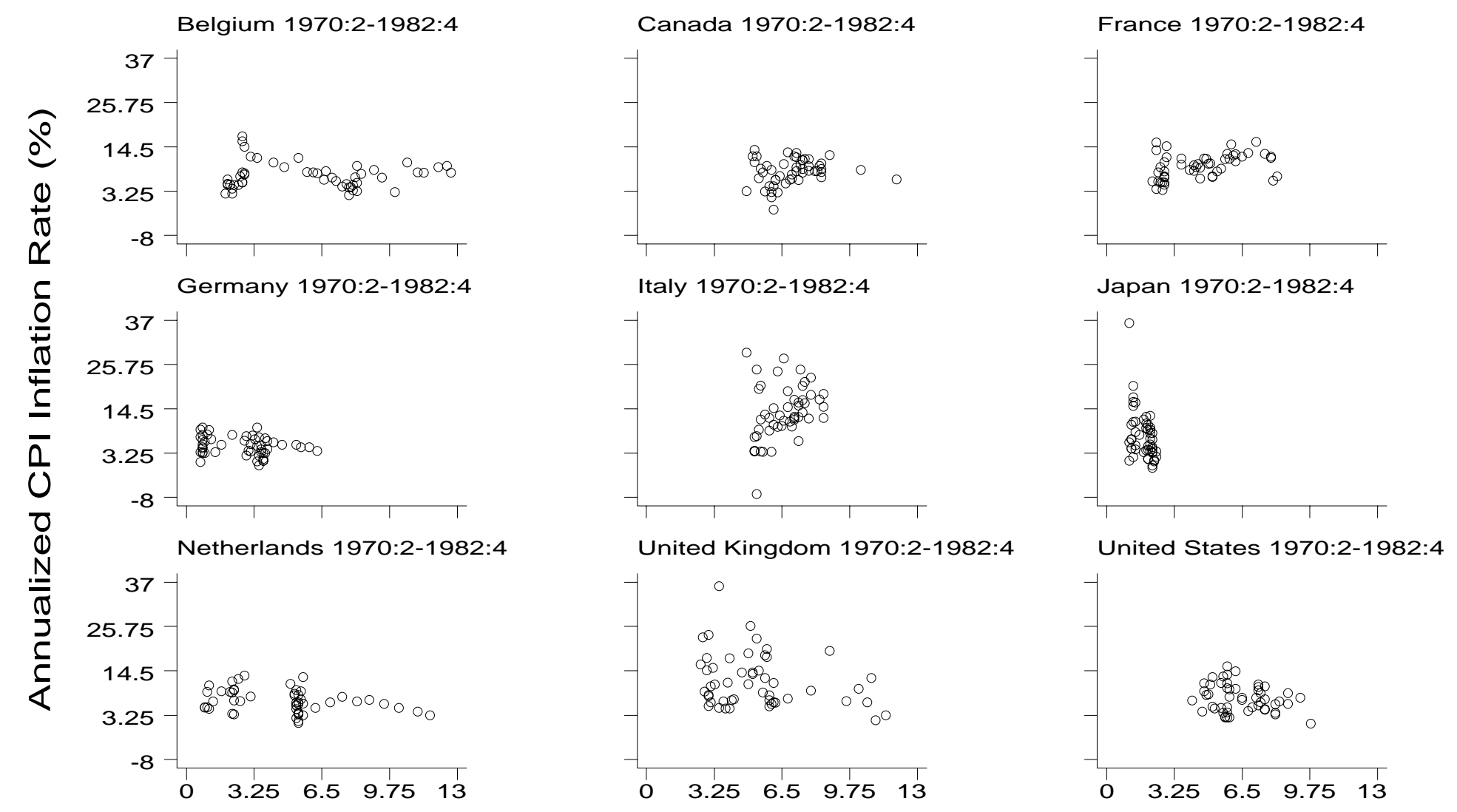

Lagged Unemployment Rate (\%)

Figure 1: Quarterly Inflation and Unemployment Before 1983 
Source: CPIs and Non-Standardized Unemployment Rates, OECD
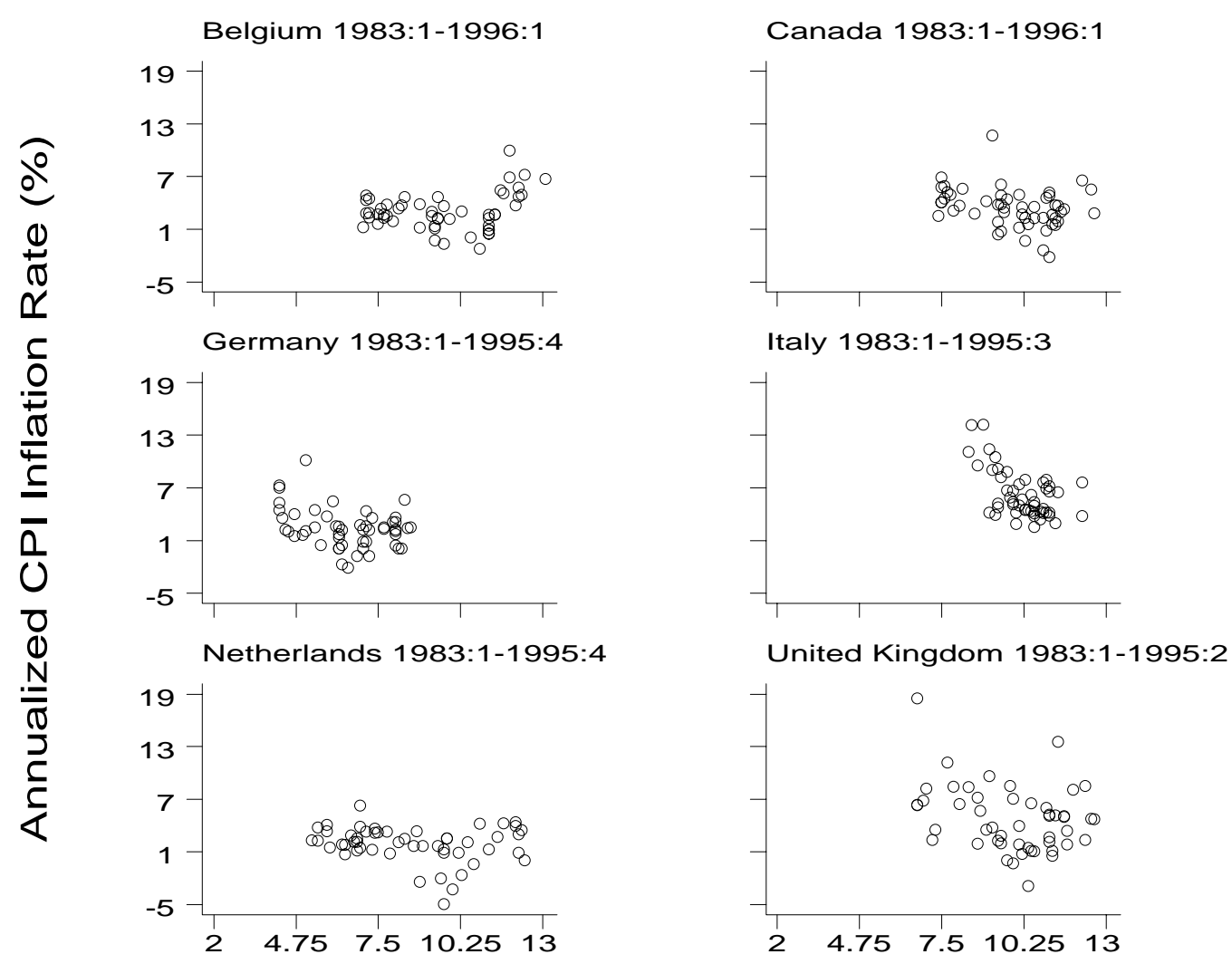

France 1983:1-1996:1

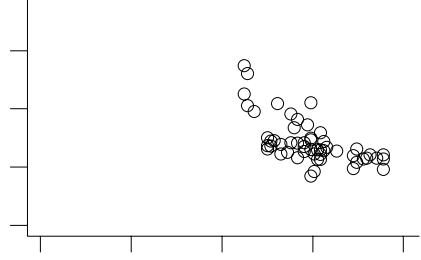

Japan 1983:1-1995:4

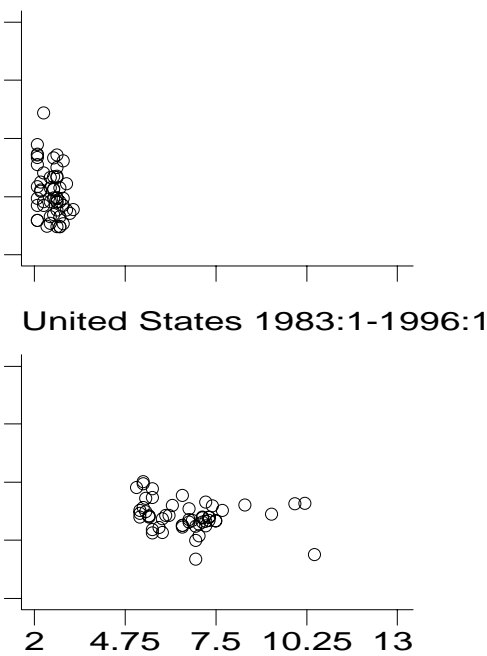

Lagged Unemployment Rate (\%)

Figure 2: Quarterly Inflation and Unemployment After 1982 
Table 1:

OLS Panel Data Phillips Curves

(Standard Errors in Parentheses)

\begin{tabular}{lccc}
\hline \hline Independent & Whole & Pre & Post \\
Variable & Sample & 1983 & 1982 \\
\cline { 2 - 4 } Lagged & & & \\
Unemployment Rate & $(0.054)$ & $(0.110)$ & -0.42 \\
& & & \\
Quarter 2 & $1.075)$ & 0.92 & 1.17 \\
& $(0.374)$ & $(0.605)$ & $(0.300)$ \\
Quarter 3 & -0.79 & -1.29 & -0.51 \\
& $(0.374)$ & $(0.605)$ & $(0.301)$ \\
Quarter 4 & -0.16 & -0.65 & 0.03 \\
& $(0.375)$ & $(0.605)$ & $(0.301)$ \\
Constant & 14.50 & 12.85 & 8.68 \\
& $(0.617)$ & $(0.939)$ & $(0.834)$ \\
Observations & & & \\
$R^{2}$ & 928 & 459 & 469 \\
\hline \hline
\end{tabular}

The dependent variable is the annualized quarterly inflation rate. Quarterly inflation rates are annualized. Regressions include country fixed effects. The omitted category is United Kingdom, first quarter. 


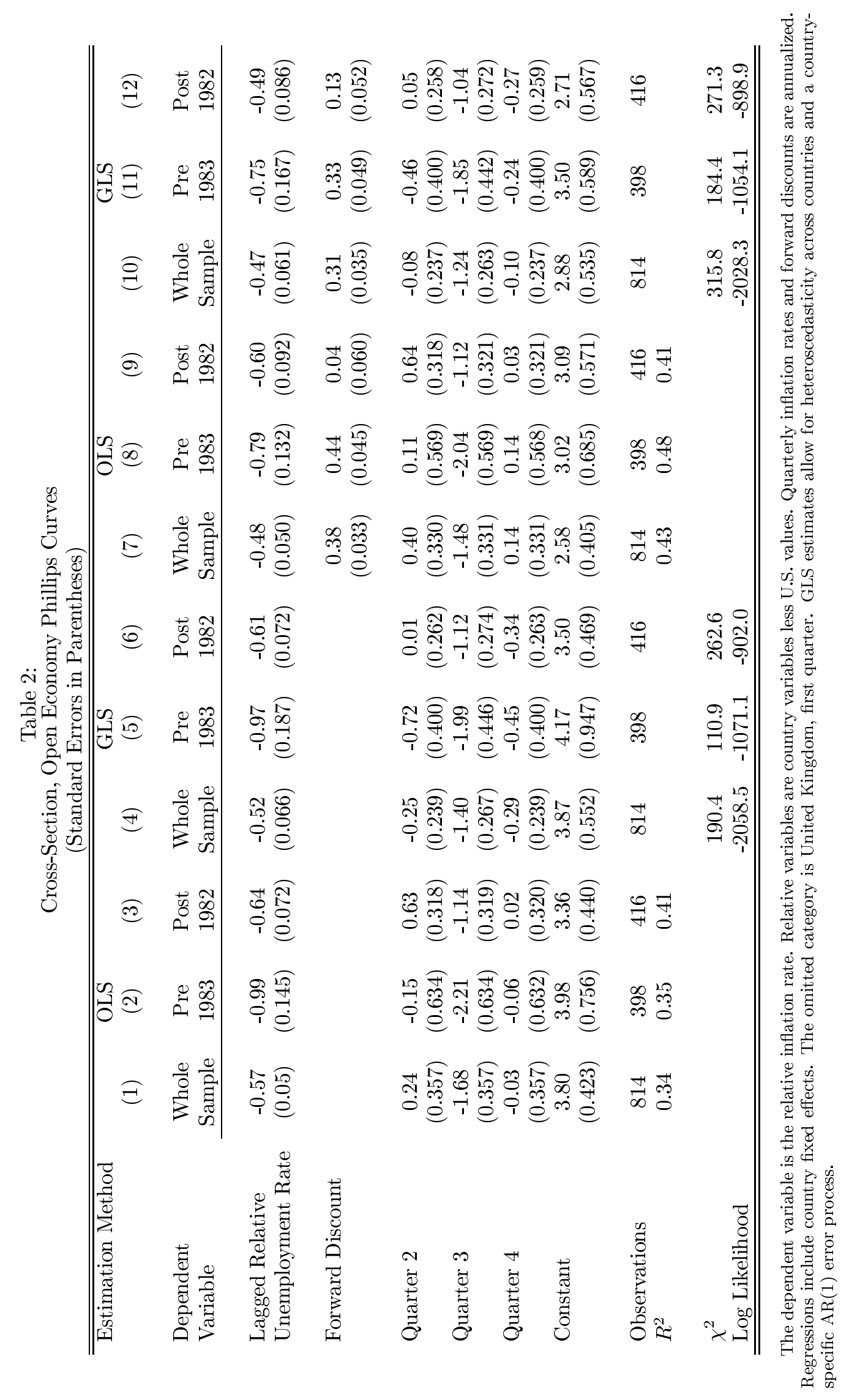


Table 3:

Time-Series, Open Economy Phillips Curves

(Standard Errors in Parentheses)

\begin{tabular}{|c|c|c|c|c|c|c|c|c|}
\hline $\begin{array}{l}\text { Independent } \\
\text { Variable }\end{array}$ & $\overline{\overline{\text { Belgium }}}$ & 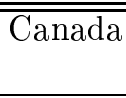 & France & Germany & 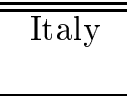 & "Japan & Netherlands & $\begin{array}{l}\text { United } \\
\text { Kingdom }\end{array}$ \\
\hline $\begin{array}{l}\text { Lagged Relative } \\
\text { Unemployment Rate }\end{array}$ & $\begin{array}{c}-0.33 \\
(0.213)\end{array}$ & $\begin{array}{l}-0.57 \\
(0.213\end{array}$ & $\begin{array}{l}-0.42 \\
(0.100)\end{array}$ & $\begin{array}{l}-0.26 \\
(0.252)\end{array}$ & $\begin{array}{l}-0.59 \\
(0.240)\end{array}$ & $\begin{array}{c}-0.12 \\
(0.457)\end{array}$ & $\begin{array}{l}-0.48 \\
(0.189)\end{array}$ & $\begin{array}{l}-0.85 \\
(0.195)\end{array}$ \\
\hline $\begin{array}{l}\text { Forward } \\
\text { Discount }\end{array}$ & $\begin{array}{c}0.31 \\
(0.088)\end{array}$ & $\begin{array}{c}0.31 \\
(0.183)\end{array}$ & $\begin{array}{c}0.23 \\
(0.068)\end{array}$ & $\begin{array}{c}0.22 \\
(0.119)\end{array}$ & $\begin{array}{c}0.35 \\
(0.084)\end{array}$ & $\begin{array}{c}0.41 \\
(0.073)\end{array}$ & $\begin{array}{c}0.14 \\
(0.127)\end{array}$ & $\begin{array}{c}0.47 \\
(0.158)\end{array}$ \\
\hline Quarter 2 & $\begin{array}{c}-1.87 \\
(0.449)\end{array}$ & $\begin{array}{l}-0.50 \\
(0.533)\end{array}$ & $\begin{array}{c}0.21 \\
(0.456)\end{array}$ & $\begin{array}{c}-2.61 \\
(0.479)\end{array}$ & $\begin{array}{l}-1.05 \\
(0.799)\end{array}$ & $\begin{array}{c}2.87 \\
(0.790)\end{array}$ & $\begin{array}{c}1.99 \\
(0.649)\end{array}$ & $\begin{array}{c}4.53 \\
(0.930)\end{array}$ \\
\hline Quarter 3 & $\begin{array}{c}-0.44 \\
(0.513)\end{array}$ & $\begin{array}{l}-0.15 \\
(0.589)\end{array}$ & $\begin{array}{l}-0.55 \\
(0.509)\end{array}$ & $\begin{array}{l}-4.02 \\
(0.544)\end{array}$ & $\begin{array}{l}-2.38 \\
(0.886)\end{array}$ & $\begin{array}{l}-1.46 \\
(0.898)\end{array}$ & $\begin{array}{l}-0.30 \\
(0.721)\end{array}$ & $\begin{array}{c}-2.59 \\
(1.021)\end{array}$ \\
\hline Quarter 4 & $\begin{array}{c}-0.90 \\
(0.445)\end{array}$ & $\begin{array}{l}-1.05 \\
(0.527)\end{array}$ & $\begin{array}{c}0.25 \\
(0.454)\end{array}$ & $\begin{array}{l}-2.68 \\
(0.481)\end{array}$ & $\begin{array}{c}1.50 \\
(0.795)\end{array}$ & $\begin{array}{c}2.03 \\
(0.791)\end{array}$ & $\begin{array}{c}1.91 \\
(0.638)\end{array}$ & $\begin{array}{c}0.27 \\
(0.937)\end{array}$ \\
\hline Constant & $\begin{array}{c}0.56 \\
(0.745)\end{array}$ & $\begin{array}{c}1.42 \\
(0.647)\end{array}$ & $\begin{array}{c}0.85 \\
(0.490)\end{array}$ & $\begin{array}{c}0.37 \\
(0.971)\end{array}$ & $\begin{array}{c}3.69 \\
(1.113)\end{array}$ & $\begin{array}{l}-1.79 \\
(2.175)\end{array}$ & $\begin{array}{l}-1.83 \\
(0.655)\end{array}$ & $\begin{array}{c}1.86 \\
(0.928)\end{array}$ \\
\hline $\begin{array}{l}\text { Post91 Indicator } \\
\text { (Germany Only) }\end{array}$ & & & & $\begin{array}{c}0.65 \\
(1.547)\end{array}$ & & & & \\
\hline Observations & 104 & 104 & 104 & 103 & 102 & 93 & 103 & 101 \\
\hline$R^{2}$ & 0.27 & 0.13 & 0.27 & 0.41 & 0.37 & 0.49 & 0.28 & 0.50 \\
\hline Original DW & 0.69 & 1.23 & 1.16 & 0.89 & 1.24 & 1.15 & 1.11 & 1.48 \\
\hline Transformed DW & 2.26 & 2.00 & 1.98 & 2.19 & 2.01 & 2.26 & 2.26 & 2.00 \\
\hline $\operatorname{AR}(1)$ Coefficient & 0.66 & 0.37 & 0.41 & 0.59 & 0.40 & 0.44 & 0.45 & 0.25 \\
\hline
\end{tabular}

The dependent variable is the relative inflation rate. Relative variables are country values less US values. Quarterly inflation rates and forward discounts are annualized. The first quarter is the omitted category. Estimates use the Prais-Winsten iterative procedure, with an $\mathrm{AR}(1)$ in the error process. 


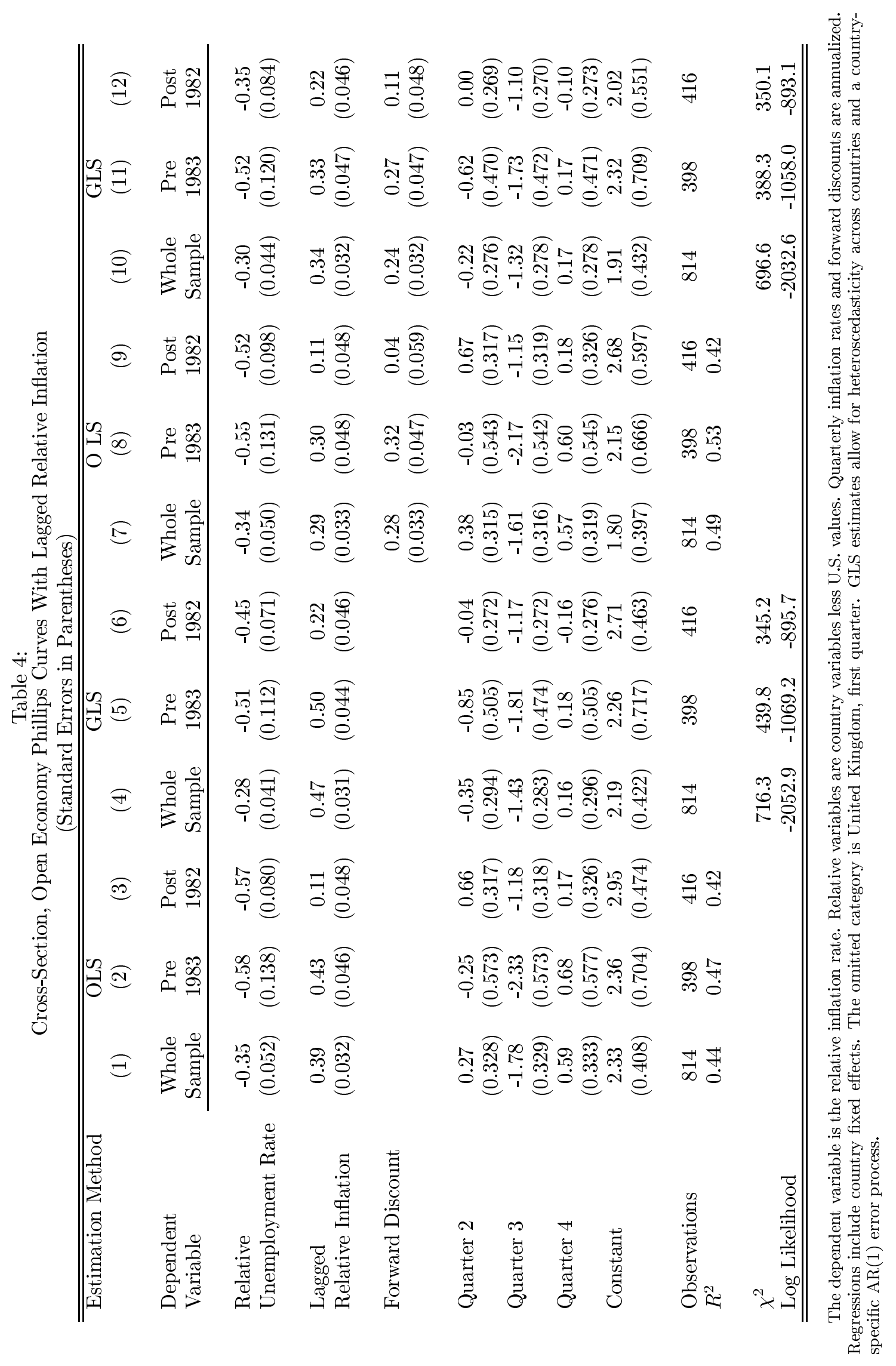

